\title{
An approach to strengthening compliance with ABET safety criteria
}

\section{Dr. Troy J. Vogel, University of Illinois, Urbana-Champaign}

Dr. Troy J. Vogel is a lecturer in the Department of Chemical \& Biomolecular Engineering at the University of Illinois at Urbana-Champaign. He primarily teaches Chemical Process Design, a senior level course. In addition to formal teaching, Dr. Vogel acts as the advisor for the Illinois Chapter of AIChE and AIChE's Chem-ECar Competition. Dr. Vogel also plays an active role in various summer camps fostering a desire to learn science and engineering in all of today's youth.

\section{Dr. David L. Tomasko, Ohio State University}

David Tomasko is a Professor of Chemical \& Biomolecular Engineering at The Ohio State University. He also serves as Associate Dean for Undergraduate Education and Student Services for the College of Engineering 
An approach to strengthening compliance with ABET safety criteria

In 2012 ABET program specific criteria for Chemical Engineering were improved to include the teaching of hazards associated with various processes. Over the past few years programs have used various methods of attaining compliance with this criteria. This work shows 2 different methods of complying with the criteria within large public universities with undergraduate student populations in excess of 700 each. One method places emphasis on integrating safety throughout the entire core curriculum within mini design projects mainly through student selflearning. The topics are then reinforced within the capstone courses during senior year. The second method places emphasis on distributing safety topics among the unit operations and senior design courses supplemented by an elective course in Chemical Process Safety. Repeated emphasis of safety alongside technical content results in a relatively strong connection to the context of chemical process operations. This paper specifically demonstrates each method and presents the results of student outcomes.

\section{Background and Motivation}

Every semester it seems as if there is a major chemical process safety incident reported which ends up in our classes as a teachable moment. Faculty in chemical engineering courses often take note of the incident, discussing it in class and perhaps following up with assignments to reinforce the importance of process safety to aspiring engineers. While this ad-hoc approach has doubtless occurred for years, the ABET program criteria for Chemical Engineering and similarly named programs now reads "The curriculum must include the engineering application of these basic sciences to the design, analysis, and control of chemical, physical, and/or biological processes, including the hazards associated with these processes." Thus, more formal approaches to safety education are needed but none of the external constraints (time and credit hours) on curriculum have eased.

Fortunately, faculty are in the habit of sharing information, ideas and best practices in our teaching and curriculum development and this paper is an example of that. Two of the authors have attended the annual AIChE-CCPS-SAChE Faculty Workshop for faculty. This workshop provides in-depth knowledge of the practical implementation of safety culture in an industrial chemical manufacturing environment. This exposure to practice along with materials provided by the workshop allow faculty to educate more comfortably and authoritatively about safety practices. We describe herein approaches from two accredited programs at major researchintensive institutions to provide examples from which others can draw. Neither program relies on the addition of a separate, required process safety course although one does offer such a course as an elective.

\section{Methods}

\section{University of Illinois at Urbana-Champaign}

The Chemical and Biomolecular Engineering program at the University of Illinois at UrbanaChampaign uses a combination of self-taught, project based, learning in the freshmen through junior years and a structured presentation of materials within the senior year. Students complete 5 mini design projects within core chemical engineering courses within their freshmen through junior years, within the chemical engineering profession survey, materials and energy balances, 
thermodynamics, fluid and heat transfer, and reactor design. The project during freshmen year is specifically an analysis of a Chemical Safety Board completed investigation including future recommendations to companies working with similar hazards. Each team is given a different incident which occurred within the last fifteen years. The students present their findings in a poster session where seniors attend and provide written feedback on both technical aspects and communication skills. Self-reflection is required following the poster presentation in an attempt to foster an intrinsic motivation to critically think about the integration of safety in all future projects.

Within sophomore and junior years students complete a mini design project in each of the fundamental chemical engineering courses. A portion of each project includes a safety component. Technical knowledge is gained from the course taken, but there is no formal covering of safety aspects specific to the project. Students are expected to expand upon their experience freshmen year and subsequent projects to develop an intrinsic motivation for selflearning in order to satisfactorily address hazard identification and safety aspects within their designs. The typical deliverable is a written report, with a section devoted to such safety aspects. Design projects range from performing an optimization on a materials balance for a process, to designing a heating/cooling system for a house, designing a pumping and piping system for various uses, and designing a reactor given a set of real kinetic data.

Students take two capstone courses during senior year which include a more formal presentation of safety topics. Within the Process Design course, students work in teams to complete a capstone project, the same for each group, to develop a process to produce a commodity chemical. Each team is required to show competency in each of the SACHE safety modules, continuing the self-learning model. Using this self-learning combined with course materials, students perform PHAs on selected process equipment within their design. The prompt is as follows:

Environmental, Health, and Safety Concerns - Indicate major environmental and safety concerns with the process. Include safety certificates from the 8 SACHE safety modules here. Perform a PHA on one reactor, and one distillation column. One PHA must be a HAZOP, the other is your choice and will not be covered in course material. Create a P\&ID for these two unit ops with the previous PHAs in mind.

The Unit Operations course offers a structured review of safety instrumented systems, laboratory, and personal safety. These topics are formally evaluated individually prior to the start of lab work.

\section{The Ohio State University}

At The Ohio State University within the Chemical and Biomolecular Engineering program, chemical process hazards, HAZOP analysis, laboratory safety, personal safety and safety in design are spread across three required courses: Unit Operations Laboratory I ( 2 credits) and II ( 2 credits), Chemical Engineering Economy and Strategy (4 credits), and CBE Process Design and Development (4 credits). This approach was adopted in the year of our last accreditation visit during a curriculum redesign brought on by a calendar change from quarters to semesters. 
In the Unit Operations courses, there are two primary learning objectives related to safety:

- Be familiar with safety issues important in the chemical industry, including laboratory safety protocols, material safety data (MSDS) sheets, and proper handling, storage, and disposal of chemicals.

- Become familiar with basic principles of emergency vents.

Safety is stressed throughout the course and university on-line modules from the university wide Environmental Health and Safety (EHS) are required before students enter the laboratory. Seven modules are required: Laboratory Standard Training, Chemical Spill Cleanup, Compressed Gas Cylinders, Toxicology, Building Emergency Action Plan (BEAP), and Hazard Communication for Laboratory Personnel. Emergency vents for pressure relief are covered in detail in a lecture introducing the "layers or protection" model of plant safety. Students are given examples of accidents and proper design of control systems. During one of the weeks, safety audit/evaluation committees are formed where every student participates. These committees are responsible for a safety audit of either a specific laboratory experiment or entire floor of the Unit Operations Laboratories at some time during the week. The committees issue a written report to the instructor citing safety violations and concerns and offering improvement suggestions.

Quizzes are used to establish knowledge of personal and laboratory safety. Chemical storage, laboratory hood use, MSDS, personal protective equipment, and spill cleanup are tested before students enter the laboratory.

Within the Economy and Strategy course, the relevant learning objective reads

- Familiarization with Process Safety.

Within the chemical process design course, process safety is the subject of the entire first exam (16\% of the grade). Approximately two weeks are dedicated to detailed coverage of process safety concepts including: Basic Concepts (Prevention/Control/Mitigation/Isolation, Global incident history, Federal regulations and industry initiatives, Pyramid Principle), Case Studies of Incidents, Process Safety Management (HAZOP Technique, Hazard identification), Runaway Reactions, Explosions and Fire Fundamentals, and Dust Hazards and Explosions. To provide an example of the level of detail, one of the questions asked on an hour exam is shown in Figure 1.

In Process Design and Development, the learning objective is:

- Be familiar with process safety issues involved in the laboratory environment and chemical process design.

The course requires completion of 5 University EHS modules which repeat those in the unit operations course (BEAP, Personal Protective Equipment, Chemical Spill Cleanup, Compressed Gas Cylinder Safety and Lab Standard Training) and 3 SAChE Modules (Process Safety Lessons Taught from Experience, Risk Analysis and Runaway Reactions). One of the 3 design projects in the course is a unique open-ended problem that may or may not involve laboratory work. A section on Safety and Risk Analysis is required in the reporting for this project as follows:

Safety and Risk Analyses - Discuss if the experiments involve any hazardous materials or dangerous procedures, and if so, your safety procedures in dealing with any potential hazards. All MSD Sheets should be attached with the report. Non-experimental projects must address this point as if the project were to be implemented. 
The feed rate to an exothermic chemical reactor needs to be monitored carefully and is controlled by the system shown below. The flow is measured by two separate flow meters, specifically two separate differential pressure (DP) cells. The first DP is connected to a flow indicator controller (FIC), which is connected to the control valve that controls the flow of feed.

You are not comfortable with having only one safety system for this feed rate system, so you decide to add a second one. You consider inserting a new, more reliable DP flow meter downstream of the control valve, connected to a high flow alarm (FAH) in the control room, as shown below. The operator in the control room, once she is alerted by the high flow alarm (FAH), can close the control valve from the control room.

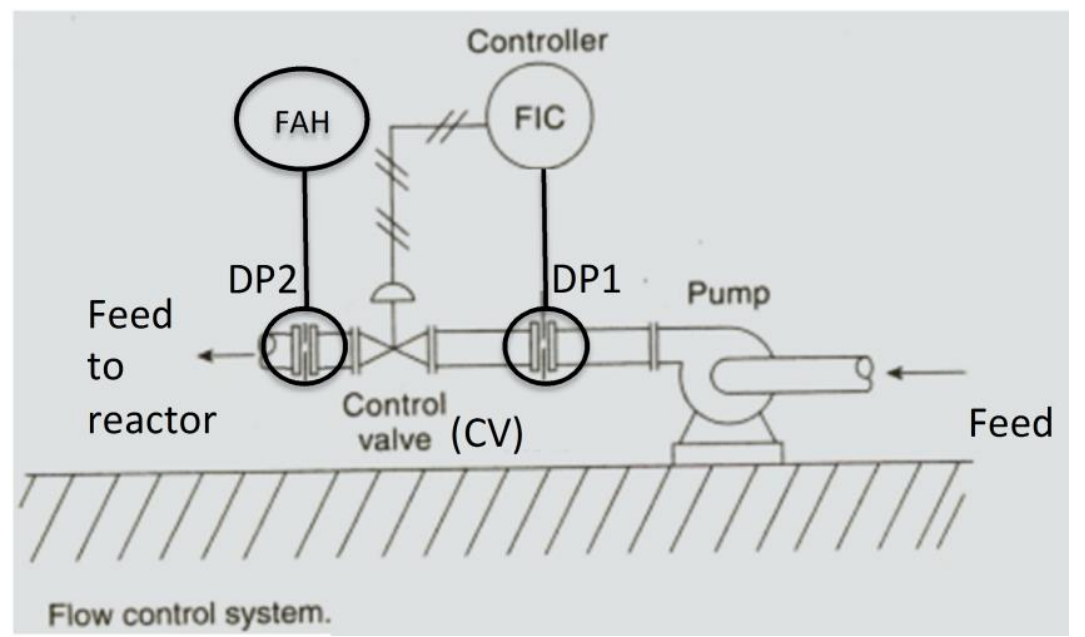

Draw a fault tree for the combined system shown above, including both control loops, leading to the top event, "Failure to control the feed flow to the reactor". Determine the reliability $(\mathrm{R})$ and the failure probability $(\mathrm{P})$ for each of the components. The failure rate $(\mu)$ of each of the components is given below. Then, determine the reliability, failure probability, overall failure rate $(\mu)$, and the MTBF (Mean Time between Failures) for the top event, "Failure to control the feed flow rate to the reactor".

\begin{tabular}{|c|c|}
\hline Component & Failure rate $(\boldsymbol{\mu})$ in failure/year \\
\hline (CV) Control Valve & 0.70 \\
\hline (FIC) Controller & 0.30 \\
\hline (DP1) Cell—Flow meter 1 & 1.50 \\
\hline (DP2) Cell—Flow meter 2 & 1.00 \\
\hline (FAH) High Flow Alarm & 0.05 \\
\hline Operator & 0.04 \\
\hline
\end{tabular}

Figure 1. Example exam question regarding fault tree analysis on feed controller to an exothermic reactor 


\section{Results}

University of Illinois at Urbana-Champaign

Senior design reports contain an Environmental, Health, and Safety Concerns section of the final project report. The departmental wide mini design projects were instituted in Spring 2011. This provided a longitudinal study looking at the effectiveness of the projects as they relate to performance within the final design projects. Averages for this section over the previous few semesters were as follows:

\begin{tabular}{|l|c|c|c|}
\hline Semester & Average & Number of Teams & $\begin{array}{c}\text { Number of mini- } \\
\text { design projects } \\
\text { completed }\end{array}$ \\
\hline Fall 2014 & $81 \%$ & 22 & 5 \\
\hline Spring 2014 & $80 \%$ & 16 & 4 \\
\hline Fall 2013 & $75 \%$ & 16 & 4 \\
\hline Spring 2013 & $58 \%$ & 8 & 3 \\
\hline Fall 2012 & $67 \%$ & 15 & 3 \\
\hline Spring 2012 & $46 \%$ & 13 & 1 \\
\hline
\end{tabular}

It can be seen that teams which completed more mini design projects, with the safety component, indicated advanced understanding of safety related material as presented within the appropriate section of the final senior design report. Even though the safety material was primarily selftaught within the mini-design projects, it does have a positive effect on presented work.

A 2 page grading guide includes questions evaluators must answer in reading. A sample is included:

- Does it seem reasonable to flare or thermally oxidize those streams indicated as such?

- Was there a HAZOP performed on an important reactor or separation tower? How complete is it? Is it easy to follow? Was information placed in the HAZOP just to have information in there so that it looked more complete? (A sign of this is if there are too many 'same as $X$ ' lines. There will be some referring back, but it shouldn't be excessive.)

- Did they give a description of the process they are performing the HAZOP on? This should include a description of the chemistry as well as a diagram. This is the first step in order to get everyone on the same page. It must be included.

$\circ$ Chemistry involved should be intended as well as unintended. The unintended chemistry can be due to impurities or just side reactions with intended substances.

- The diagram really should be a P\&ID. It should include all valves and other safety systems. For this class, it does not need to include a complete control system (however it likely will include a mostly complete one). They should be labeled using a consistent system in order to accurately reference them in the HAZOP.

- Was the PHA specific to the reactor complete?

$\circ$ Was the potential for a runaway reaction discussed (if exothermic reactions)? Was a runaway temperature calculated? (it can be based on the reaction which would runaway first in the system of reactions) 
○ Did they conclude that pressure relief valves and rupture disks were needed? Did they estimate the pressure at which they want each to trip? Pressure relief should be sufficiently lower than the rupture disk.

- Did they size either valve, disk, or piping? Remember that a relieving gas can have a max linear velocity of Mach 1, known as choked flow.

- Was the PHA specific to the separation tower complete?

- Were flammability and explosive limits explored?

- Did the group list the environmental concerns chemicals in their process possess?

○ Mitigative safeguards?

- Emissions limits? (specific levels are better than generalities, generalities are better than nothing) EPA limits are set individually, based on industry and location. A detailed estimation of EPA permitting is beyond the scope of this class.

- Did the group list the health and safety of workers with regard to the chemicals in their process?

○ Mitigative safeguards? PPE? (eg. Personal $\mathrm{H}_{2} \mathrm{~S}$ concentration devises are often employed when there is a significant concern)

- Permissible exposure levels (PEL)? (specific levels are better than generalities, generalities are better than nothing)

- Did the students include SACHE safety certificates in the 9 sections as required?

Evaluators are given a range of sample graded work which is used to calibrate evaluation. Each team is individually evaluated, some teams choose to explore some areas more than others. In the past groups have given a plant layout with an evacuation plan, detailed EPA estimated emissions, and a very detailed fault tree analysis. Teams are not given this set of questions, but they are used as an evaluation guide. Teams which choose to explore one aspect in depth are not penalized for a superficial analysis of one section. We believe that the overall scores for this section gives a good indication of how well a team addresses hazards associated with the processes designed.

Individual accountability for safety content is within the second exam in the senior design course and within the first exam in the unit operations course.

\section{The Ohio State University}

Students are required to attend 4 lectures related to laboratory and personal safety in the Unit Operations course one of which is delivered by the Safety Coordinator from the Department of Chemistry and Biochemistry to demonstrate the university level commitment to this subject. The assignment to carry out safety audits in a department laboratory or on an experimental apparatus provides direct assessment of student knowledge of process hazards. Scores from the SP 2014 offering on the quiz covering process safety lectures ranged from $67.5 \%$ to $96.8 \%$ with a mean of $86.1 \%(\mathrm{~N}=193)$. In the Economy and Strategy course, the first exam grades ranged from $74 \%$ to $100 \%$ with a mean of $93.6 \%(\mathrm{~N}=94)$. An example exam question is shown in Figure 1 to present the level of difficulty and depth in the subject matter.

Self-reported assessments of learning objectives have been included in Economy and Strategy and Process Design and Development. The question is two-fold asking the students to rate on a 5 -point scale how confident they are in having met the objective $(1=$ low confidence, $5=$ high 
confidence) and how well the course contributed to their having met the objective $(1=$ poor, $5=$ excellent). The results from both questions on the safety learning objectives are generally positive with $75-80 \%$ of students responding 4 or 5 on the confidence scale in having met the objective and $60-70 \%$ responding 4 or 5 on the contribution of the course to their having met the objective.

We also asked the students how they would prefer that safety topics be integrated into the curriculum. The students are generally split on the value of having content in all three courses with a significant fraction reporting a preference for having it in only the Unit Operations course and one of the design courses.

\section{Conclusion}

We believe the approach used at the University of Illinois at Urbana-Champaign has many benefits which can expand beyond the time at the university. Developing a student into a lifelong learner is essential to the success of our graduates and also a student outcome for the program. We use this approach within the context of the entire mini-design structure as it is a natural fit. By giving students many opportunities to iteratively learn and receive feedback before more formal safety instruction within the senior year, students have truly improved performance. One challenge with this approach is that students within groups can sometimes hide, not gaining the skills and knowledge associated with the assigned group project. However, this approach has 2 gate keeping courses in the senior year which have individual components which can catch those hiding in groups.

We believe the approach used at The Ohio State University has benefits associated with coordination among the upper level courses. The optional course with strong focus on chemical process safety is one which is gaining more popularity through the years both from our students and our employers. One challenge associated with the approach is that evaluation of the safety component within the process design and development is a challenge as each project presents unique hazards, some more complex than others. This too is alleviated with the personal responsibility and accountability of material on the individual level through formal course material.

The examples above demonstrate distributed approaches to incorporating chemical process safety and personal safety in existing chemical engineering curricula. Since safety is a tangible characteristic of chemical engineering operations it is easily justified as a course topic in the eyes of both faculty and students. Each program heavily utilizes the SAChE safety modules as well as university based safety training. Faculty training from industrial experience or at least the AIChE-CCPS-SAChE Faculty Workshop is critical to the authentic implementation of these topics. We have shown that direct assessments from exams and student reports demonstrate a significant attainment of knowledge in the area and indirect assessments point to the desire of students to see this material integrated into the unit operations and design courses. Both programs presented here have been continuously accredited since 1936 . As the reader will appreciate, there is no formula for guaranteeing successful accreditation but the examples provided here may find use in other chemical engineering programs or other programs with the desire to include a safety component to their degree. 